\title{
An organisational participatory research study of the feasibility of the behaviour change wheel to support clinical teams implementing new models of care
}

Eleanor R Bull ${ }^{1,2^{*}}$ D, Joanne K Hart ${ }^{1}$, Juliette Swift ${ }^{3}$, Kirstie Baxter ${ }^{3}$, Neil McLauchlan ${ }^{3}$, Sophia Joseph ${ }^{1}$ and Lucie M T Byrne-Davis ${ }^{1 *}$

\begin{abstract}
Background: Health and social care organisations globally are moving towards prevention-focussed communitybased, integrated care. The success of this depends on professionals changing practice behaviours. This study explored the feasibility of applying a behavioural science approach to help staff teams from health organisations overcome psychological barriers to change and implement new models of care.

Methods: An Organisational Participatory Research study was conducted with health organisations from North West England, health psychologists and health workforce education commissioners. The Behaviour Change Wheel (BCW) was applied with teams of professionals seeking help to overcome barriers to practice change. A mixedmethods data collection strategy was planned, including qualitative stakeholder interview and focus groups to explore feasibility factors and quantitative pre-post questionnaires and audits measuring team practice and psychological change barriers. Qualitative data were analysed with thematic analysis; pre-post quantitative data were limited and thus analysed descriptively.

Results: Four clinical teams from paediatrics, midwifery, heart failure and older adult mental health specialties in four organisations enrolled, seeking help to move care to the community, deliver preventative healthcare tasks, or become more integrated. Eighty-one managers, medical doctors, nurses, physiotherapists, midwives and other professionals contributed data. Three teams successfully designed a BCW intervention; two implemented and evaluated this. Five feasibility themes emerged from the thematic analysis of qualitative data. Optimising the BCW in an organisational change context meant 1) qualitative over quantitative data collection, 2) making behavioural science attractive, 3) co-development and a behavioural focus, 4) effective ongoing communication and 5) support from engaged leaders. Pre-post quantitative data collected suggested some positive changes in staff practice behaviours and psychological determinants following the intervention.
\end{abstract}

Conclusions: Behavioural science approaches such as the BCW can be optimised to support teams within health and social care organisations implementing complex new models of care. The efficacy of this approach should now be trialled.

Keywords: Organisational change, Behavioural science, Qualitative research, Feasibility studies, Healthcare organisation and delivery, Health services organizations

\footnotetext{
* Correspondence: e.bull@mmu.ac.uk; lucie.byrne-davis@manchester.ac.uk

${ }^{1}$ Division of Medical Education, University of Manchester, Oxford Road,

Manchester M139PT, UK

Full list of author information is available at the end of the article
}

(c) The Author(s). 2019 Open Access This article is distributed under the terms of the Creative Commons Attribution 4.0 International License (http://creativecommons.org/licenses/by/4.0/), which permits unrestricted use, distribution, and reproduction in any medium, provided you give appropriate credit to the original author(s) and the source, provide a link to the Creative Commons license, and indicate if changes were made. The Creative Commons Public Domain Dedication waiver (http://creativecommons.org/publicdomain/zero/1.0/) applies to the data made available in this article, unless otherwise stated. 


\section{Background}

Globally, health and social care is changing rapidly, with countries making large-scale reorganisations to enable more integrated, person-centred and cost-effective care [1]. In England and Wales, The Wanless Report advocated for prevention and self-management; increased integration between primary, secondary, tertiary and social care; relocation of hospital services to the community; and more home-based care [2]. The Five Year Forward View in England [3] reiterated this, with 50 'NHS New Care Model Vanguard Sites' commissioned in England in 2015, to develop blueprints for new care models [4]. Sustainability and Transformation Partnerships, the next iteration, go even further, urging widespread changes aiming to improve care and deliver efficiency in England [5].

Implementing new models of care is a complex behaviour change intervention [6], requiring commissioners, managers, practitioners, and service users to do things differently [7]. Traditional approaches to implementing policy using regulation and incentives may neglect the vital understanding of individual staff in their context, required to 'help individuals who work in the NHS make local change happen' [8], p1. Service transformation at scale requires macro, meso and micro level organisational change to be viewed together, in the context of day-to-day staff practice [9].

Implementation science researchers study health professional behaviour change both by applying classical theories of behaviour to explain health professional practice [10] and by testing theory-based intervention development approaches, including the Behaviour Change Wheel (BCW), synthesised from 18 other behavioural frameworks $[11,12]$. The BCW is an approach to behaviour change intervention development centred on three types of psychological determinants required in to enact any behaviour. Understanding these capability (knowledge and skills), opportunity (physical and social environmental barriers) and motivation (both automatic habits and views of pros and cons) barriers to behaviour change for a health professional or group of professionals then enables linkage to different intervention and policy functions to support change (e.g. education, persuasion, guidelines). When designing interventions to overcome barriers, the $\mathrm{BCW}$ also recommends specifying specific behaviour change techniques (BCTs) within an intervention [13]. The BCW has been applied to improving sepsis recognition and management [14], diabetes care [15] and energy use [16] and in evaluation of health checks [17], but not yet in organisational changes known as 'new models of care'.

$\mathrm{BCW}$ intervention publications tend to focus more on design than implementation [18] and on content rather than process [19]. Yet for global impact in real-world settings, implementation and evaluation is crucial [20], something well recognised in traditional organisational change theories [21] and in some intervention development approaches. For example, Intervention Mapping [22] more explicitly and clearly defines implementation and the French et al. [23] model emphasises evaluation. Moreover, applying the $\mathrm{BCW}$ in large-scale healthcare change may require a flexible research design enabling co-development and refinement with partners. One such healthcare improvement research approach is Organisational Participatory Research (OPR) [24]. OPR emphasises academic and non-academic partners collaborating systematically effect change in an organisation including an 'iterative research cycle of planning, action and fact finding about the effect of the action' [25].

Recent evaluations of NHS new care model vanguard sites indicate that implementing organisational change in practice has been a key challenge and that developing shared understandings of local challenges is vital, before testing, evaluating and adapting approaches for continuous improvement [26]. This suggests that a $\mathrm{BCW}$ approach with an OPR design may be timely and useful. However, it is unclear both whether the BCW's focus on health professional behaviour change would be attractive to key stakeholders such as organisational change leaders who may be more macro-level focussed, and how to maximise feasibility and efficacy. This study, taking an OPR approach [24], aimed to explore use of the BCW in implementing new models of care, addressing two research questions:

1. To what extent is the $\mathrm{BCW}$ a feasible approach to support teams to change within new models of care?

2. How can we optimise $\mathrm{BCW}$ feasibility in this context?

\section{Methods \\ Design}

This was an OPR study between academic and non-aca demic partners. OPR was chosen to enable co-design and refinement of interventions taking into account health system complexities and diversity. Academic partners were health psychologists from the University of Manchester, non-academic partners were Health Education England working across the North West (HEENW), and health and social care NHS new care model vanguard sites in the North West of England. Following OPR practice guidance, a working group was established at study inception with $3 \mathrm{HEE}$ and 3 academic researcher stakeholders, who met regularly throughout to jointly manage the programme [25]. NHS new care model vanguard site leads, and team members were consulted throughout; due to their limited time availability they did not join the working group [27]. Given the focus on healthcare 
reorganisation and healthcare staff behaviour change, service users were not directly involved in this feasibility study, although would be useful contributors to further work [25].

\section{Participants / study population}

Teams of health and social care professionals from NHS new care model vanguard sites in the North West of England were recruited. We aimed to recruit diverse teams from across the different 'types' of NHS new care model vanguard sites including those integrating primary and acute care; moving specialist care to the community; linking hospitals together; joining-up care for older people; and coordinating emergency care [28]. The study and its secondary data analysis met criteria for operational improvement activities exempt from ethical review at the University of Manchester. Participants gave verbal consent to data collection and were assured that they could withdraw from data collection activities at any time.

\section{Intervention}

The study aimed to apply the $\mathrm{BCW}$ [14] to help each recruited team to identify key service delivery (behaviour) change required to implement their new model of care, understand barriers and and co-develop an evidencebased, tailored behaviour change intervention to assist implementation. The three stages in the BCW are 1) Understanding the behaviour and determinants, 2) Identifying intervention options (functions and policy categories), and 3) Identifying content and implementation options (including BCTs and mode of delivery).

\section{Procedure}

HEENW sent initial invitation letters to NHS new care model vanguard site leads in the North West of England in May 2016, followed up with email invitations and opportunistic conversations, and meetings with working group members. Interested leads nominated a team from their site having difficulties task shifting, expanding or changing practice to implement new models of care. OPR was thus sought and driven by organisation members directly, an important predictor of success [25]. The $\mathrm{BCW}$ was then applied over 18 months, led by the academic partners based on expertise and experience co-developing $B C W$ interventions $[29,30]$. Initial results were incorporated into ongoing decision-making and discussions to help optimise applying the $\mathrm{BCW}$ [25].

\section{Planned data collection}

A mixed-methods data collection strategy was planned at four key timescales. Exploring feasible data collection methods was part of the study so were not fixed at project inception.
Qualitative methods planned were one-to-one semistructured interviews with team members, (in person or on telephone), focus groups with team members, written communications, field notes and observations of practice conducted by EB and JS. Semi-structured interview and focus group guides were developed by the working group through literature reviews and discussions with leads and team members and were applied flexibly depending on participant roles, interests and experiences by EB and JS. Interviews and focus groups were audiorecorded where participants consented to this, and audio files were transcribed verbatim anonymously by a professional company and deleted; detailed notes were taken where there were no audio-recordings, anonymous field notes were typed up; qualitative data stored securely.

Quantitative data planned were numeric audit data from observations of practice, questionnaires co-deve loped with teams to assess staff participant views of the determinants of practice behaviours, based on the $\mathrm{CO}$ M-B Framework [13] and routinely-collected service evaluation data shared by team leads. COM-B questionnaires, designed using the $\mathrm{BCW}$ guide, asked participants to rate their views on physical and psychological capability, social and physical opportunity and automatic and reflective motivation determinants of the behaviour in question, such as for example 'my colleagues would like me to run a heart failure clinic in the community each week' for social opportunity. Ratings were using likert scales $(1=$ strongly disagree, $5=$ strongly agree $)$, with some reverse scored to enhance response validity. Specific behavioural determinants were selected from interview data at $\mathrm{T} 1$ and $\mathrm{T} 2$. Where self-rated behavioural data were collected, participants estimated the number of times they had engaged in the desired behaviour in the previous week. Questionnaires were co-designed and piloted with teams where possible. Quantitative data were entered into a database, with all stored securely on a password protected computer.

\section{Planned analyses}

Qualitative data (transcripts and notes) were thematically analysed using both inductive and deductive analysis across timepoints of the study by SJ and EB. Initial inductive coding relevant to feasibility and efficacy was conducted, a coding schedule agreed, further transcripts analysed separately using Nvivo (v.12) before comparing with recursive discussion and revision of the coding framework. SJ then independently analysed the remaining qualitative data. Theory-led deductive coding was applied by EB to identify capability, opportunity and motivation determinants of practice as part of the $\mathrm{BCW}$ process.

We planned to analyse quantitative data by grouping questionnaire scores, quantitative audit data and service 
level data collected from the various teams to identify common determinants across varied practice behaviours and test for statistical pre-post intervention differences using SPSS (v.22).

\section{Results}

\section{Participants and intervention focus}

Participant flow is included in Fig. 1, and NHS new care model vanguard site and participant characteristics are described in Table 1. In brief, four of seven local sites were enrolled (labelled A-D), collectively serving a population of over three million. We worked with Vanguards $\mathrm{A}$ and $\mathrm{C}$ to design, implement and evaluate a $\mathrm{BCW}$ intervention over 18 months, Vanguard D designed but did not implement a BCW intervention over 12 months, Vanguard B worked with us over six months and did not finish designing a $\mathrm{BCW}$ intervention. The four teams of professionals identified covered diverse specialties across the lifespan (paediatrics, midwifery, heart failure, older adult mental health). Eighty-one health professionals contributed data; $89 \%$ were women, and there were a wide range of staff cadres (Table 1). Teams chose behaviours related to three types of new care model: integrated working, moving care into the community and expanding preventive roles respectively.

\section{Data collected and analysed}

Participants each participated in several types of data collection across the project, described in Table 2. Data collected and analysed were from 50 individual interviews and 11 focus groups or discussion groups held with 57 participant (7 and 3 audio-recorded respectively) observation of 33 team members practicing, a practice audit repeated twice, two sets of questionnaires completed by 20 participants at least once, fieldnotes and two sets of routinely-collected data. All teams contributed data at T1 and T2, A and C to T3 and T4. Quantitative data were analysed descriptively; inferential stati stics were not applied given small sample sizes. Questionnaire data collected only at T2 were used solely to target the intervention (see also additional file 1); questionnaire data collected both pre and post (T2-T4)

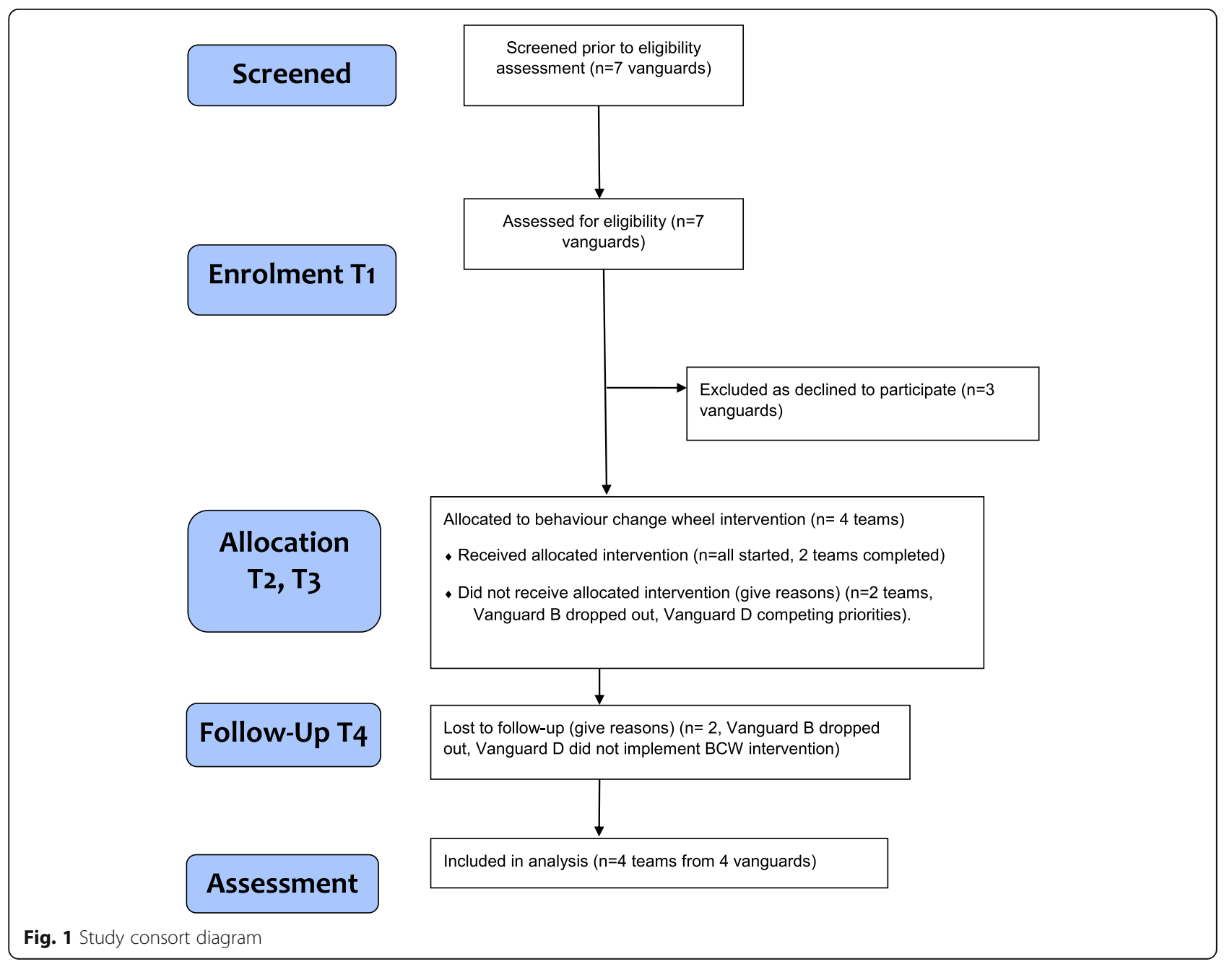


Table 1 Vanguard Organisation characteristics

\begin{tabular}{|c|c|c|c|c|c|c|}
\hline Vanguard & $\begin{array}{l}\text { Aim of new } \\
\text { model of care }\end{array}$ & $\begin{array}{l}\text { Organisation } \\
\text { partners }\end{array}$ & $\begin{array}{l}\text { Local } \\
\text { population } \\
\text { reach [4] }\end{array}$ & Team(s) & $\begin{array}{l}\text { Health } \\
\text { professional } \\
\text { participants }\end{array}$ & $\begin{array}{l}\text { Behavioural } \\
\text { focus of the } \\
\text { intervention }\end{array}$ \\
\hline A & $\begin{array}{l}\text { Integrated primary } \\
\text { and acute care } \\
\text { systems vanguard: } \\
\text { Multi-disciplinary } \\
\text { integrated care }\end{array}$ & $\begin{array}{l}5 \text { partners (incl city } \\
\text { council, hospital and } \\
\text { mental health trusts, } \\
\text { CCGs) }\end{array}$ & 230,000 & $\begin{array}{l}\text { Integrated health } \\
\text { and social care } \\
\text { team in an older } \\
\text { adult acute mental } \\
\text { health unit. }\end{array}$ & $\begin{array}{l}n=36(29 \\
\text { women, } 7 \\
\text { men) } \\
10 \text { Trainee/ } \\
\text { qualified } \\
\text { nurses } \\
6 \text { Vanguard } \\
\text { leads/senior } \\
\text { managers } \\
6 \text { Nursing/activity } \\
\text { assistants } \\
\text { 3Trainee/qualified } \\
\text { physiotherapists } \\
3 \text { Medical doctors } \\
2 \text { Trainee/qualified } \\
\text { psychologists } \\
2 \text { Trainee/qualified } \\
\text { occupational therapists } \\
2 \text { Ward managers } \\
1 \text { Speech and language } \\
\text { therapist } \\
1 \text { Ward clerk }\end{array}$ & $\begin{array}{l}\text { Increasing the } \\
\text { effectiveness of multi- } \\
\text { disciplinary integrated } \\
\text { working: } \\
\text { Ward team instigating } \\
\text { more cross-disciplinary } \\
\text { recovery-focussed activ- } \\
\text { ities with patients. }\end{array}$ \\
\hline B & $\begin{array}{l}\text { Integrated primary } \\
\text { and acute care } \\
\text { systems vanguard: } \\
\text { Multi-disciplinary } \\
\text { integrated care }\end{array}$ & $\begin{array}{l}11 \text { partners (incl } \\
\text { NHS trusts, } \\
\text { ambulance services, } \\
\text { CCGs, local authorities, } \\
\text { GP federations) }\end{array}$ & 356,000 & $\begin{array}{l}\text { Integrated children's } \\
\text { nursing } \\
\text { community team }\end{array}$ & $\begin{array}{l}n=10 \text { ( } 9 \text { women, } \\
1 \text { man) } \\
3 \text { Vanguard leads } \\
\text { and senior } \\
\text { vanguard } \\
\text { managers } \\
3 \text { Team leaders } \\
3 \text { children's } \\
\text { specialist nurses } \\
1 \text { service director }\end{array}$ & $\begin{array}{l}\text { Enhancing use of a new } \\
\text { integrated service: } \\
\text { Increasing referrals from } \\
\text { acute staff to a new } \\
\text { specialist holistic } \\
\text { children's nursing team }\end{array}$ \\
\hline C & $\begin{array}{l}\text { Multi-specialty } \\
\text { community } \\
\text { providers vanguard: } \\
\text { Moving specialist } \\
\text { care into the } \\
\text { community }\end{array}$ & $\begin{array}{l}6 \text { partners (ind local } \\
\text { councils, } \\
\text { hospital trusts and } \\
\text { CCGs) }\end{array}$ & 320,000 & $\begin{array}{l}\text { Heart failure } \\
\text { specialist team. }\end{array}$ & $\begin{array}{l}n=15 \text { ( } 14 \text { women, } 1 \text { man) } \\
5 \text { Heart failure } \\
\text { specialist nurses } \\
\text { ( } 3 \text { acute and } 2 \\
\text { community nurses) } \\
2 \text { Administrators } \\
2 \text { Healthcare assistants } \\
2 \text { OD practitioners } \\
1 \text { Vanguard lead } \\
1 \text { Clinical lead doctor } \\
1 \text { Psychologist } \\
1 \text { Physiotherapist }\end{array}$ & $\begin{array}{l}\text { Moving specialist care } \\
\text { into the community: } \\
\text { Acute heart failure team } \\
\text { beginning to run one } \\
\text { clinic in the community } \\
\text { per week. } \\
\text { Community heart failure } \\
\text { team redirecting non- } \\
\text { specialist referrals back } \\
\text { to primary care to in- } \\
\text { crease capacity }\end{array}$ \\
\hline D & $\begin{array}{l}\text { Acute Care } \\
\text { Collaboration } \\
\text { Vanguard Site: } \\
\text { New care pathways } \\
\text { through a network for } \\
\text { women and children's } \\
\text { services and engaging } \\
\text { more with local helping } \\
\text { people to help them } \\
\text { better manage their } \\
\text { own health. }\end{array}$ & $\begin{array}{l}29 \text { organisations and } \\
\text { networks (incl CCGs, } \\
\text { hospital providers, } \\
\text { and an ambulance } \\
\text { service) }\end{array}$ & $\begin{array}{l}\text { Up to } 2.4 \\
\text { million }\end{array}$ & $\begin{array}{l}\text { Community } \\
\text { midwifery team. }\end{array}$ & $\begin{array}{l}n=20 \text { ( } 20 \text { women) } \\
13 \text { Community midwives } \\
5 \text { Team leads /senior } \\
\text { midwives } \\
1 \text { Vanguard lead } \\
1 \text { Clinical lead midwife }\end{array}$ & $\begin{array}{l}\text { Increasing the } \\
\text { prevention and self- } \\
\text { management role of } \\
\text { midwives: } \\
\text { Community midwives } \\
\text { starting to offer the 'flu } \\
\text { vaccination to every } \\
\text { pregnant woman in } \\
\text { their care. }\end{array}$ \\
\hline
\end{tabular}

intervention used to evaluate the intervention are presented in the results below.

\section{Intervention delivery and outcomes}

The BCW interventions developed with three teams are summarised in Table 3. Interventions designed targeted combinations of $\mathrm{C}, \mathrm{O}$ and $\mathrm{M}$, through four types of intervention functions and policy categories, and 13 BCTs. Intervention design and delivery with teams $\mathrm{A}$ and $\mathrm{C}$ are fully described in Additional files 1 and 2 .

In the seven-day audit of rehabilitation activities in Vanguard A, 17 activities were held pre-intervention, 18 
post-intervention. 'Types' of activity leader involved doubled, from 4 pre-intervention to 8 post-intervention, including patients In Vanguard $C$, the limited pre-post questionnaire data collected from acute nurses $(n=2)$ suggested that for $\mathrm{C}$ and $\mathrm{O}$ determinants, plans and expectation to run clinics in community increased post-intervention, with scores on the 5-point 'plans' scale doubling (mean 1.67 to mean 3.5;see Additional file 2).

\section{Feasibility themes}

The inductive thematic analysis of qualitative data revealed 5 main themes identifying to what extent the $\mathrm{BCW}$ was a feasible approach for this context and how to optimise this. These were:

Qualitative data is most feasible, Making behavioural science attractive, Key mediators: Co-development and a behavioural focus, Ongoing communication with teams Support from engaged leaders, discussed below.

\section{Qualitative data is most feasible}

Analysis of field notes from initial meetings and communications revealed that team leads felt qualitative data most feasible to collect. Some reported this would be most efficacious, giving deeper insights into barriers and facilitators of practice change, others that it would engage team members in the project through providing a listening space, others that it would help build rapport. Equally in this theme, field notes suggested managers feared that asking teams to complete quantitative COM -B questionnaires would make them feel 'tested' or watched, disengaging them. Additionally, it was noted that service-level data was not easily shared with the working group, because of reservations about data protection; quantitative observation and audit were revealed as most acceptable forms of quantitative data collection.

\section{Making behavioural science attractive}

This theme included interviews and field notes, where it was noted that engaging Vanguards in the BCW was challenging, beginning with reaching decision makers in hugely complex, multi-layered organisations. Concerted, repeated contacts with many layers of health service management were required. For Vanguards deciding not to participate, written communications suggested they did not see the relevance of the programme, for instance one Vanguard lead from a non-participating vanguard optimistically expressed:

'I don't think we need this programme as our teams are all fully integrated' Vanguard lead, written communication from HEENW.

Another Vanguard lead was concerned about perception of behavioural science and of time demands in engaging teams:

It will be a real help, we just need to persuade them that's what they need and it's not management mumbo-jumbo: clinicians have a natural distrust for behavioural methodology ... also a 'phone chat' may be more appealing than calling it interviews' Vanguard B lead, T1, individual interview.

Attractive and informative communications about the programme were required, a 'reflective loop' taken by the working group to optimise the programme. The brand 'Teams Together', a colourful logo, short PowerPoint presentation and animation about the $\mathrm{BCW}$ developed by the programme team (available at http:// www.mcrimpsci.org/elearning/) at T1 to communicate the programme effectively. In another reflective loop, a Vanguard lead advised including more evidence about

Table 2 Data collection from health professional participants across the study

\begin{tabular}{|c|c|c|c|c|c|c|c|c|c|c|c|c|c|c|c|}
\hline & \multirow[b]{3}{*}{ Vanguard } & \multicolumn{14}{|c|}{ Study time point } \\
\hline & & \multicolumn{4}{|c|}{ T1: Enrolment } & \multicolumn{4}{|c|}{ T2:Intervention design } & \multicolumn{3}{|c|}{$\begin{array}{l}\text { T3:Intervention } \\
\text { implementation }\end{array}$} & \multicolumn{3}{|c|}{$\begin{array}{l}\text { T4:Post-intervention } \\
\text { evaluation }\end{array}$} \\
\hline & & $A$ & $B$ & $C$ & $D$ & $A$ & $B$ & $C$ & $D$ & $A$ & $B$ & $C D$ & $A$ & $B$ & C \\
\hline \multirow[t]{4}{*}{$\begin{array}{l}\text { Qualitative } \\
\text { data }\end{array}$} & $\begin{array}{l}\text { Discussion/focus } \\
\text { groups }\end{array}$ & $n=6$ & $\begin{array}{l}n= \\
5\end{array}$ & & & $n=14$ & $n=3$ & $n=14$ & $n=19$ & & & & & & $n=1$ \\
\hline & Individual interviews & $n=2$ & $\begin{array}{l}n= \\
2\end{array}$ & $\begin{array}{l}n= \\
2\end{array}$ & $\begin{array}{l}n= \\
2\end{array}$ & $n=27$ & & & & & & $\begin{array}{l}n= \\
1\end{array}$ & $n=13$ & & \\
\hline & $\begin{array}{l}\text { Written communication } \\
\text { and field notes }\end{array}$ & $\begin{array}{l}5 \\
\text { pieces }\end{array}$ & & & & $\begin{array}{l}40 \\
\text { pieces }\end{array}$ & $\begin{array}{l}22 \\
\text { pieces }\end{array}$ & $\begin{array}{l}26 \\
\text { pieces }\end{array}$ & $\begin{array}{l}12 \\
\text { pieces }\end{array}$ & $\begin{array}{l}10 \\
\text { pieces }\end{array}$ & & & $\begin{array}{l}15 \\
\text { pieces }\end{array}$ & & $\begin{array}{l}4 \\
\text { pieces }\end{array}$ \\
\hline & Observation data & & & & & $n=32$ & & & $n=2$ & & & & & & \\
\hline \multirow{3}{*}{$\begin{array}{l}\text { Quantitative } \\
\text { data }\end{array}$} & Questionnaires & & & & & & & $n=5$ & $n=15$ & & & & & & $n=2$ \\
\hline & Audit of team practice & & & & & 1 audit & & & & & & & 1 audit & & \\
\hline & $\begin{array}{l}\text { Routinely-collected } \\
\text { data }\end{array}$ & & & & & & & 1 set & 1 set & & & & & & \\
\hline
\end{tabular}

$n=$ numbers of staff included where number of participating staff involved were counted 
Table 3 Summary of BCW interventions designed with 3 Vanguard teams

\begin{tabular}{|c|c|c|c|}
\hline & Vanguard A & Vanguard C & Vanguard D \\
\hline Summary of intervention focus & Integrated care in psychiatric ward & $\begin{array}{l}\text { Moving heart failure care to } \\
\text { community }\end{array}$ & $\begin{array}{l}\text { Midwives offering preventive 'flu } \\
\text { vaccine }\end{array}$ \\
\hline $\begin{array}{l}\text { Relevant psychological determinants } \\
\text { identified (C, O or M) }\end{array}$ & $\mathrm{C}, \mathrm{O}$ and $\mathrm{M}$ & $\begin{array}{l}\text { Community sub-team: } \mathrm{O} \\
\text { Acute sub-team: } \mathrm{O} \text { and } \mathrm{M}\end{array}$ & $\mathrm{C}$ and $\mathrm{O}$ \\
\hline Intervention functions proposed & $\begin{array}{l}\text { Persuasion } \\
\text { Environmental restructuring } \\
\text { Training }\end{array}$ & $\begin{array}{l}\text { Enablement } \\
\text { Environmental restructuring } \\
\text { Persuasion }\end{array}$ & $\begin{array}{l}\text { Training } \\
\text { Environmental restructuring }\end{array}$ \\
\hline Relevant policy categories & $\begin{array}{l}\text { Environmental/social planning } \\
\text { Service provision } \\
\text { Guidelines }\end{array}$ & $\begin{array}{l}\text { Communication/marketing } \\
\text { Environmental/social } \\
\text { planning } \\
\text { Service provision }\end{array}$ & $\begin{array}{l}\text { Service provision } \\
\text { Environmental/social planning }\end{array}$ \\
\hline BCTs proposed (from [12]) & $\begin{array}{l}\text { 1. Information about health } \\
\text { consequences } \\
\text { 2. Information about social and } \\
\text { environmental consequences } \\
\text { 3. Instruction on how to perform } \\
\text { behaviour } \\
\text { 4. Demonstration of behaviour } \\
\text { 5. Action planning } \\
\text { 6. Restructuring physical environment } \\
\text { 7. Restructuring the social environment } \\
\text { 8. Reviewing behavioural goals }\end{array}$ & $\begin{array}{l}\text { Community sub-team: } \\
\text { 1. Behavioural substitution } \\
\text { 2. Social support (practical) } \\
\text { 3. Adding objects to the } \\
\text { environment } \\
\text { Acute sub-team: } \\
\text { 4. Feedback on behaviour } \\
\text { 5. Behavioural experiment. } \\
\text { 6. Action planning } \\
\text { 7. Environmental restructuring }\end{array}$ & $\begin{array}{l}\text { 1. Adding objects to the } \\
\text { environment } \\
\text { 2. Demonstration of behaviour } \\
\text { 3. Instruction of how to perform } \\
\text { the behaviour }\end{array}$ \\
\hline
\end{tabular}

$\mathrm{BCW}$ to engage clinical colleauges. Fieldnote data suggested this optimised the attractiveness of the $\mathrm{BCW}$, for instance:

'These materials are very helpful for homing in and clarifying..we can pair the programme with an existing innovation and project'. Vanguard C Lead, T1, individual interview.

Within this theme, another aspect documented in interviews and field notes concerned explaining the $\mathrm{BCW}$ to non-psychologist colleagues. Reflexive fieldnotes from initial meetings suggested behaviour change terminology used in the BCW should be simplified, and intervention implementation and evaluation emphasised to optimise engagement in a $\mathrm{BCW}$ intervention in this context. For instance one senior manager in Vanguard A commented:

'So this behaviour change wheel helps you make a programme to help the staff but what is going to happen and who is going to actually do it and evaluate it - is there support? We'd worry about sustainability.' Vanguard A senior manager, T1, focus group meeting.

To optimise feasibility, as a key reflective loop, we developed a five-phase process to implement the $\mathrm{BCW}$ in this context, summarised in Fig. 2. Stage 1 of the BCW corresponds to the identifying and exploring phases, stage 2 and 3 are contained within the deciding phase.
Key mediators: Co-development and a behavioural focus A third feasibility theme concerned how the intervention was perceived to work. T4 evaluation data suggested that co-development and collaboration as well as a behavioural focus had been essential ingredients, or mediators of changes in capability, opportunity and motivation determinants and behaviours. The motivation and confidence-building process of staff becoming actively involved in change, through the $\mathrm{BCW}$ and facilitated by the OPR approach was seen as vital to the success of the programme, as discussed by a ward manager:

It was so important that the staff wanted to focus on activities and rehab.... it came from the staff and the away days in particular helped bring out the importance of recovery for people and get their own ideas out for how to change things ... it sparked new ideas that we could work on. Now everyone is spurred up and their ideas are brilliant' Vanguard A ward manager, T4, individual interview.

Co-development also meant that tailoring was possible, for timescales, $\mathrm{BCW}$ content and delivery methods. Team members themselves were encouraged to deliver BCTs from the behaviour change wheel, such as the team champion delivering rehabilitation coaching. It was important to consider who could be the deliverers of interventions especially those aiming to build motivation, to be a 'credible source' for teams. 
Taking a behavioural approach was generally appreciated by frontline staff who felt this operationalised and personalised new care models, as in an interview in T4:

"They [away days] were definitely beneficial, no doubt about it, it gave some structure and a forum in which to say that that is what everybody wants to do, everybody has got their own things that they think should be happening and it gave everybody a place to voice their ideas." Assistant Occupational Therapist, Vanguard A, T4, individual interview.

Equally, managers felt that this approach helped specify the changes, such as the clinical lead in vanguard $\mathrm{C}$ :

"Teams Together helped me define what we have to do into just two or three changes" Clinical lead, Vanguard $\mathrm{C}, \mathrm{T} 3$, written communication.

However, teams and vanguard leads varied in how easy they found specifying a behaviour. Field note analyses suggested that teams who had a clearer idea of what changes may mean for their pathway were more 'ready' for the approach and could immediately see its relevance, and some wanted help with 'decision making' which is not overtly behavioural.
'It is more about the decision making, we all know what we need to do but it's how to get there that is a problem'. Vanguard Lead B, T1, individual interview.

All teams focussed on behaviours they wished to 'start' doing or do more of rather than 'stop' doing or do less of.

\section{Ongoing communication with teams}

Across timepoints, analysis of fieldnotes particularly emphasised the importance of regular communication when taking an OPR approach, where weeks could pass without face-to-face meetings with team members. Interestingly, feeding back to teams, which is an essential aspect of OPR, was most feasible with a 'low-tech' approach to this feedback, using flip charts and post-it notes, and displays around the wards. Interviewees reported this helped them feel they could contribute to ideas and the results were not already finalised. Highlighting positive behaviours and team strengths observed during feeding back also helped engage teams. Paper-based solutions were also useful in Vanguard C's behavioural experiment: the patient survey had been originally conceived on an ipad, but after delays and technical difficulties, there was more success with a simple

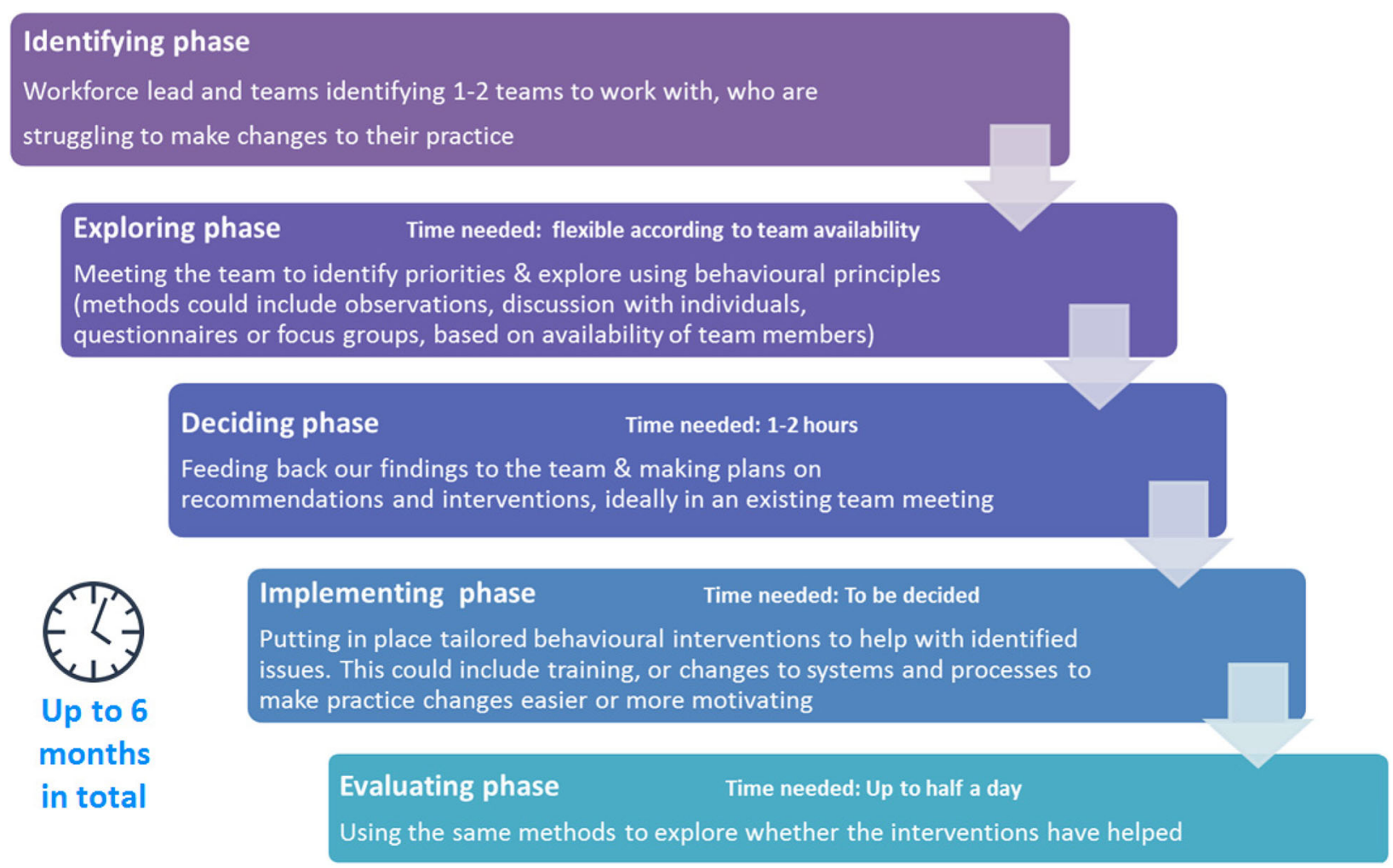

Fig. 2 Five stage process of the Teams Together Programme 
printed sheet, which nurses managed to distribute rapidly to numerous patients.

In vanguard $\mathrm{A}$, the first to reach the deciding phase, a report was disseminated by email and copies left on the ward, as well as a PowerPoint presentation, delivered at the first away day and distributed via email. Informal enquiries suggested few team members had read even the executive summary of this report, despite the report being heavily pictorial and colourful. In work with the later teams, colourful one-page summaries seemed a more acceptable means of communication about $\mathrm{BCW}$ interventions happening in teams.

\section{Support from engaged leaders}

Finally, a vital recurring feasibility theme from qualitative data was support from engaged leaders, crucial to embed and champion the programme. In Vanguard B, behaviours were difficult to identify since several team leaders involved had conflicting ideas about new models of care aims and implementation. Field note analysis reflected on the difficulty that in this Vanguard, a key team leader appeared to have low motivation for the behaviour change chosen by others, therefore unsurprisingly did not offer support for a $\mathrm{BCW}$ intervention to help their team implement it, a factor influencing the difficulties maintaining Vanguard B's engagement in the programme.

Furthermore some leaders who were themselves in favour of the change but suspected their teams to have motivational barriers, initially felt that engaging in the programme could be too strong a personal endorsement of the change, causing relationship problems with teams. In Vanguard A, the T4 interview with a manager yielded the invaluable insight that investing time and public support in a $\mathrm{BCW}$ could at first feel risky:

"It was quite overwhelming when you first came.. it was just me ... .my thoughts about what they might say to you, whether it would be all negative when you spoke to them, whether it would work and they would be better or if it wouldn't work and things would get worse. But in fact it's been the opposite, it's all been really positive" Vanguard A manager, T4, individual interview.

Reflective field notes compared this with the co-development approach taken by team C's leader, a clinician who decided to present the team with the clinical evidence suggesting the need to change, and enabled them to draw their own conclusions about what behaviour changes could be needed, which she then restated as options.

Internal support and leadership was also seen as important to sustaining a $\mathrm{BCW}$ intervention. In interviews with frontline staff from vanguard A at T4, several team members were concerned about ongoing sustainability where the team leader had encouraged the staff group and the academic partner to lead the intervention. One health care assistant commented:
'There has not been a leader ... .someone more senior who would have led it and chased it up and that ... .someone who is here all the time ... chasing it up, making sure it is being done daily until everybody gets into that rhythm'. Healthcare assistant, Vanguard A, $\mathrm{T} 4$, individual interview.

Internal leadership may also have shielded the programme from competing demands which delayed planned interventions in vanguards $C$ and $D$. In an interview with vanguard lead $D$ when the planned intervention implementation had been on hold for several months, she suggested that time pressures were to blame:

"I mean I think they were actually really keen for you to do the, from a midwifery perspective, that follow-up training you were going to do with them. It has definitely been the added time pressure constraints ... they've just been unlucky in terms of a number of things that have factored in with extra training they had to do these last few months, a lot of pressure" Vanguard D lead, T3, individual interview.

Nevertheless, the team from Vanguard A almost unanimously agreed that $\mathrm{BCW}$ development needed to be led by an 'outsider' who they felt offered a fresh perspective, an unbiased view of team dynamics and a behavioural scientist's skills:

"I think it's good to have a psychologist taking on that role. I think just because you can see things from different angles and understand ... being able to engage with people and make them feel comfortable to talk to $[. .$.$] having a wider understanding I think of$ teams and team dynamics is useful." Nurse vanguard A, T4, individual interview.

\section{Discussion}

In an OPR study, academic and non-academic partners developed and implemented $\mathrm{BCW}$-based health professional change interventions with teams from NHS England Vanguards implementing new models of care. We identified behaviours and explored barriers with four teams, developed interventions with three teams; implemented and evaluated interventions with two teams, collecting qualitative and some quantitative data to explore how to optimise feasibility. Five feasibility 
themes emerged from analysis of the qualitative data collected, emphasising the importance of engaging the right health service partners from complex and dynamic organisations through co-development and effective communication about behavioural science.

One feasibility theme summarised participants' view that the behavioural approach to interventions was a key mediator of change. The selection of behaviours in a $\mathrm{BCW}$ intervention is not always straight forward and health professionals may struggle to define and prioritise behaviours, an area where psychologists may play a useful role [31]. Yet, in most behaviour changes (aside from environmental changes automatically cueing new behaviours) people must be aware of what behaviours to change: our findings illustrate that staff did not know what the new model of care meant they should do differently and this would certainly lead to a lack of change. We also found that behaviours chosen for the $\mathrm{BCW}$ intervention tended to be those teams wanted to start or do more of, not less of or stop. This may be because these were most easy for teams to conceptualise. Behaviours vary from each other in several key dimensions and at present behavioural science has no typology of behaviours to categorise them [32, 33]. Further scientific work in this area would help define and study which may be most appropriate for a $\mathrm{BCW}$ intervention in this context.

Additionally the finding that co-development was an important perceived mediator of change and aspect of feasibility has implications for policy makers, organisational change practitioners and managers involved in service redesign. Co-development is a key principle of the OPR approach itself [24], but also resonates with the organisational change literature, where there is increasing emphasis on co-development and co-creation of interventions [34], aimed at ensuring sustaining change and an engaged workforce. The NHS Constitution also pledged that staff would be empowered to drive changes in their health and social care organisations [35]. However, our feasibility themes suggested that this was a unique aspect of the programme uncommon in staff's experiences of implementing new models of care. Indeed, other exploratory work we conducted, discussed elsewhere, found evidence that staff perceive top-down, prescribed change in new models of care as being both a cause and consequence of poor workplace culture for teams [36]. Health psychology approaches such as the $\mathrm{BCW}$ can be a tool to put change back in the hands of the team, supporting self-efficacy and this was appealing to managers keen to implement change whilst wary of putting extra demands on teams. However, our study also underlined the importance of the methods and principles of application. The feasibility data emphasised that the $\mathrm{BCW}$ must be applied in partnership with teams rather than to conduct a study on them, which builds on our understanding about using behavioural science in practice. Policy makers and managers may find that co-designed and implemented, behaviourally-focussed interventions may help the NHS deliver on some of the aims of the NHS Constitution and improve staff work engagement. Organisational change practitioners may also benefit from training adding the $\mathrm{BCW}$ or other behavioural approaches to their toolbox.

The feasibility themes highlighted engagement, time and leadership as important issues. It seems ironic that teams could be too busy struggling with changing to benefit from support to make the change, but others note the time and effort needed from motivated individuals to begin to spark intra-organisational health partnerships [37]. As we expected, an important part of optimising feasibility involved implementation and evaluation, including extending the BCW's three stage intervention development process. It may also be that engagement and ownership would be further increased by having team representatives, if not clinical leads, as well as service users, at working group meetings.

This study has several limitations, not least that its flexible design came at the cost of not collecting substantial quantitative data. We focussed only on teams' practice behaviour and psychological determinants, without measuring service-level indicators of team performance and successful implementation of new models of care such as staff sickness and turnover, staff engagement or burnout. These would be important indicators in a future feasibility trial. The four teams we worked with, although diverse and representing a range of new models of care, were local to North West England. Further work is needed both to collect efficacy data and sample from a wider range of teams.

\section{Conclusions}

Overall, this OPR study to explore BCW feasibility suggests that $\mathrm{BCW}$ may be a helpful approach for teams who are the ultimate pathway in implementing large-scale organisational change. Attention to the process of developing and implementing implementation science inte rventions is important, with feasibility maximised through co-development, strong leadership and effective communication about behavioural science.

\section{Additional files}

Additional file 1: Vanguard A Case Study (.doc file) case study illustrating application of the BCW with the team in Vanguard A (DOCX $16 \mathrm{~kb}$ )

Additional file 2: Vanguard C Case Study (.doc file) case study illustrating application of the BCW with the team in Vanguard $C$ (DOCX $15 \mathrm{~kb})$ 


\section{Abbreviations}

BCT: Behaviour Change Technique; BCW: Behaviour Change Wheel; HEE: Health Education England; OPR: Organisational Participatory Research

\section{Acknowledgements}

We gratefully acknowledge the excellent support and participation of the dedicated staff working in our partner health and social care vanguard organisations, who do so much to improve the health and wellbeing of communities in the North West of England.

\section{Funding}

This study was funded through a grant from the non-academic partner Health Education England North West. Authors JS, KB and NM are employed by Health Education England. JS and KB were involved in the study design, JS was involved in data collection, JS, KB and NM were involved in writing the manuscript.

\section{Availability of data and materials}

Anonymised quantitative data and qualitative data transcripts are available from the corresponding author on reasonable request.

\section{Authors' contributions}

$L L B, J H, J S$ and KB conceived the study, LLB, JH, JS, KB and EB designed the study, EB led the data collection with JS, SJ and EB analysed the data, EB, JH and LLB led the writing of the manuscript, to which all authors contributed. All authors read and approved the final manuscript.

\section{Ethics approval and consent to participate}

The study met criteria for operational improvement activities exempt from ethical review at the University of Manchester. The secondary analysis of data for research purposes was granted an ethics exemption from the University of Manchester. All participants taking part in qualitative and quantitative data collection gave their verbal consent to participate and were assured that their participation was voluntary. No identifying details of any individual person are included in the manuscript: there are no clinical details, images or videos of any patient, parent, guardian, staff member in this manuscript.

\section{Consent for publication}

Participants providing qualitative or quantitative data for this study offered their consent for their data to be analysed and published for research purposes. No identifying details of any individual person are included in the manuscript: there are no clinical details, images or videos of any patient, parent, guardian, staff member in this manuscript.

\section{Competing interests}

The authors declare that they have no competing interests.

\section{Publisher's Note}

Springer Nature remains neutral with regard to jurisdictional claims in published maps and institutional affiliations.

\section{Author details}

${ }^{1}$ Division of Medical Education, University of Manchester, Oxford Road, Manchester M139PT, UK. ²Department of Psychology, Manchester Metropolitan University, Manchester M156GX, UK. ${ }^{3}$ Health Education England working across the North West, 3rd Floor, 3 Piccadilly Place, Manchester M1 3BN, UK.

\section{Received: 31 October 2018 Accepted: 7 January 2019}

\section{Published online: 04 February 2019}

\section{References}

1. Armitage G, Suter E, Oelke N, Adair C. Health systems integration: state of the evidence. Int J Integr Care. 2009;9:e82.

2. Wanless D. Securing good health for the whole population. London: HM Stationery Office; 2004.

3. NHS England. Five Year Forward View. London: NHS England; 2014. https:// www.england.nhs.uk/wp-content/uploads/2014/10/5yfv-web.pdf Accessed 25 Jun 2018.
4. NHS England. New Care Models. 2018 https://www.england.nhs.uk/newcare-models/ Accessed 03 Jul 2018.

5. NHS England. Sustainability and Transformation Partnerships. https://www. england.nhs.uk/integratedcare/stps/ Accessed 30 Jun 2018.

6. Ham C. Making sense of integrated care systems, integrated care partnerships and accountable care organisations in the NHS in England: The King's Fund; 2018. https://www.kingsfund.org.uk/publications/making-senseintegrated-care-systems. Accessed 20 Jun 2018.

7. Goffman E. In: American Sociology Association, editor. Frame Analysis- An Essay on the Organization of Experience. Cambridge: Harvard University Press; 1975.

8. Allcock C. It's all about the people: how national policy makers can better support change in the NHS. The Health Foundation. Health Foundation Blog. 2015 http://www.health.org.uk/blog/it's-all-about-people-hownational-policy-makers-can-better-support-change-nhs. Accessed 03 Jul 2018

9. Effective Practice and Organisation of Care (EPOC). EPOC Taxonomy; 2015. https://epoc.cochrane.org/epoc-taxonomy. Accessed 25 Jun 2018.

10. Eccles MP, Mittman BS. Welcome to implementation science. Implement Sci. 2006;1:1.

11. Michie S, van Stralen MM, West R. The behaviour change wheel: a new method for characterising and designing behaviour change interventions. Implement Sci. 2011;6:42.

12. Michie S, Richardson M, Johnston M, Abraham C, Francis J, Hardeman W, et al. The behavior change technique taxonomy ( 1 1) of 93 hierarchically clustered techniques: building an international consensus for the reporting of behavior change interventions. Ann Behav Med. 2013;46:81-95.

13. Michie S, Atkins L, West R. The behaviour change wheel. A guide to designing interventions. 1st ed. Great Britain: Silverback Publishing; 2014.

14. Steinmo S, Fuller C, Stone SP, Michie S. Characterising an implementation intervention in terms of behaviour change techniques and theory: the 'Sepsis Six'clinical care bundle. Implement Sci. 2015;11:14.

15. Handley MA, Harleman E, Gonzalez-Mendez E, Stotland NE, Althavale P, Fisher $\mathrm{L}$, et al. Applying the COM-B model to creation of an IT-enabled health coaching and resource linkage program for low-income Latina moms with recent gestational diabetes: the STAR MAMA program. Implement Sci. 2016;11:73.

16. Wilson C, Marselle MR. Insights from psychology about the design and implementation of energy interventions using the behaviour change wheel. Energy Res Soc Sci. 2016;19:177-91.

17. Alexander KE, Brijnath B, Mazza D. Barriers and enablers to delivery of the healthy kids check: an analysis informed by the theoretical domains framework and COM-B model. Implement Sci. 2014;9:60.

18. Barker F, Atkins L, de Lusignan S. Applying the COM-B behaviour model and behaviour change wheel to develop an intervention to improve hearing-aid use in adult auditory rehabilitation. Int J Audiol. 2016;55:S90-8.

19. Sinnott C, Mercer SW, Payne RA, Duerden M, Bradley CP, Byrne M. Improving medication management in multimorbidity: development of the MultimorbiditY COllaborative medication review and DEcision making (MY COMRADE) intervention using the behaviour change wheel. Implement Sci. 2015;10:132.

20. Ridde $\mathrm{V}$. Need for more and better implementation science in global health BMJ Global Health. 1(2). https://doi.org/10.1136/bmjgh-2016-000115.

21. Kotter International. The 8-Step Process for Leading Change - Kotter International. 2016. http://www.kotterinternational.com/the-8-step-processfor-leading-change/. Accessed 03 Jul 2018.

22. Bartholomew LK, Parcel GS, Kok G. Intervention mapping: a process for developing theory and evidence-based health education programs. Health Educ Behav. 1998 Oct;25(5):545-63.

23. French SD, Green SE, O'Connor DA, McKenzie JE, Francis JJ, Michie S, Buchbinder R, Schattner P, Spike N, Grimshaw JM. Developing theoryinformed behaviour change interventions to implement evidence into practice: a systematic approach using the theoretical domains framework. Implement Sci. 2012;7:38.

24. Waterman $H$, Tillen D, Dickson $R$, De Koning K. Action research: a systematic review and guidance for assessment. Health Technol Assess (Winchester, England). 2001;5(23):iii.

25. Bush PL, Pluye P, Loignon C, Granikov V, Wright MT, Pelletier JF, et al. Organizational participatory research: a systematic mixed studies review exposing its extra benefits and the key factors associated with them. Implement Sci. 2017;12:119. 
26. Starling A. Some assembly required: implementing new models of care lessons from the new care models programme. London; 2017. http://www.health.org. uk/sites/health/files/SomeAssemblyRequired.pdf. Accessed 30 Jun 2018

27. Bush PL, Tremblay, MC, OPR Recommendations Working Group. Organizational participatory research: Practice guide.http://reseau1quebec. ca/wp-content/uploads/2017/11/OPR_Practice_Guide_Final_commCDS.pdf Accessed on 20 Jun 2018.

28. NHS England. New care models: vanguards - developing a blueprint for the future of NHS and care services. NHS England: London. 2016. https://www. england.nhs.uk/wp-content/uploads/2015/11/new_care_models.pdf

29. Byrne-Davis LM, Bull ER, Burton A, Dharni N, Gillison F, Maltinsky W, Mason C, Sharma N, Armitage CJ, Johnston M, Byrne GJ. How behavioural science can contribute to health partnerships: the case of the change exchange. Glob Health. 2017;13(1):30.

30. Bull ER, Mason C, Junior FD, Santos LV, Scott A, Ademokun D, Simião Z, Oliver WM, Joaquim FF, Cavanagh SM. Developing nurse medication safety training in a health partnership in Mozambique using behavioural science. Glob Health. 2017;13(1):45.

31. Byrne-Davis LMT, Bull ER, Hart J. Methods to help non-psychologists to identify the health professional behaviours that need to change. $32^{\text {nd }}$ annual conference of the European Health Psychology Society; 201821 25th august Galway Ireland. European Health Psychologist proceedings. 2018:20:6.

32. Wood RE. Task complexity: definition of the concept. Organ Behav Hum Decis Process. 1986;37:60-82.

33. Wood RE, Mento AJ, Locke EA. Task complexity as a moderator of goal effects: a meta-analysis. J Appl Psychol. 1987;72:416-23.

34. Chartered Institute of Personnel and Development. The CIPD Profession Map Our Professional Standards. 2015. https://www.cipd.co.uk/Images/the-cipdprofession-map-standard-format_tcm18-9814.pdf. Accessed 30 Jun 2018.

35. Department of Health. The NHS Constitution. London: Department of Health; 2015. https://assets.publishing.service.gov.uk/government/uploads/ system/uploads/attachment_data/file/480482/NHS_Constitution_WEB.pdf. Accessed 03 Jul 2018.

36. Bull ER, Byrne-Davis LMT, Swift J, Baxter K, McLauchlan N, Hart JK. Exploring what teams mean by 'culture' when implementing new models of care. Int J Qual Health Care. 2018. mzy200, https://doi.org/10.1093/intghc/mzy200.

37. Tropical Health and Education Trust. Starting a Health Partnership. 2017. https://www.thet.org/wp-content/uploads/2017/09/How-to-start-a-HealthPartnership.pdf. Accessed 14 Jun 2018.

Ready to submit your research? Choose BMC and benefit from:

- fast, convenient online submission

- thorough peer review by experienced researchers in your field

- rapid publication on acceptance

- support for research data, including large and complex data types

- gold Open Access which fosters wider collaboration and increased citations

- maximum visibility for your research: over $100 \mathrm{M}$ website views per year

At BMC, research is always in progress.

Learn more biomedcentral.com/submissions 